\title{
Análise microbiológica de água de poços para abastecimento urbano, na cidade
} de Campina Grande-Paraíba

\author{
Mayana Morais de Sousa ${ }^{1}$, Heitor Salles da Costa Lima ${ }^{2}$, Renally Cardoso Farias ${ }^{3}$, Mayra da Silva Cavalcant ${ }^{4}$, Fábio \\ Giovanni de Araújo Batista ${ }^{5}$ Gustavo Amaro Trajano 6. \\ UNIFACISA - Centro Universitário, ${ }^{1}$ mayanamorais $26 @$ gmail.com; ${ }^{2}$ heitorsallescosta@ hotmail.com; \\ ${ }^{3}$ cardosorenally2019@gmail.com; ${ }^{4}$ mayra_cavalcanti@yahoo.com.br; $;{ }^{5}$ fabioelara@gmail.com, \\ gustavoatrajano@hotmail.com.
}

\begin{abstract}
RESUMO: Objetivou-se neste trabalho avaliar a qualidade das águas dos poços artesianos relacionando indicadores microbiológicos com possíveis risco a saúde coletiva e ambiental, a fim de subsidiar ações preventivas na cidade de Campina Grande - PB. A pesquisa foi iniciada com divisão das áreas de coleta e abrangeu quatro regiões da cidade; região norte, leste, sul e oeste. Foram selecionados poços específicos para coleta das amostras e a partir disso houve a distribuição dos pontos de amostragem. Realizadas cinco coletas em quatro poços durante os meses de Junho a Agosto de 2016. Verificou-se por meio das análises que a região Sul apresentou o maior número de contaminação por coliformes termotolerantes e contaminação em todas as amostras por E.Coli. em relação aos demais poços avaliados na Região norte apresentou contaminação baixa de coliformes termotolerantes e ausência de contaminação por E. Coli, na região Leste e Oeste apresentaram contaminação por coliformes termotolerantes e ausência de contaminação por $E$. Coli. A presença de E.coli e coliformes totais encontrados na água provavelmente pode estar associada à proximidade dos poços à percursos de redes de esgotos. Diante do exposto, dos poços monitorados demonstra que a água é imprópria para o consumo humano, sendo necessário utilização de técnicas de tratamento.
\end{abstract}

PALAVRAS-CHAVE: Contaminação; Coliformes termotolerantes; Tratamento.

ABSTRACT: The objective of this study was to evaluate the water quality of artesian wells relating microbiological indicators with possible risk to collective and environmental health, in order to subsidize preventive actions in the city of Campina Grande - PB. The research began with division of collection areas and covered four regions of the city; northern, eastern, southern and western regions. Specific wells were selected for sample collection and from this there was the distribution of the sampling points. Five collections were carried out in four wells from June to August 2016. It was verified by the analysis that the South region presented the highest number of thermotolerant coliform contamination and E. coli contamination in all samples. Compared to the other wells evaluated In the North Region showed low contamination of thermotolerant coliforms and absence of E. Coli contamination, in the East and West region showed contamination by thermotolerant coliforms and absence of E. Coli contamination. The presence of $E$. coli and total coliforms found in the water may probably be associated with the proximity of wells constructed with sewage pathways. Given the above, the monitored wells show that the water is unfit for human consumption, requiring the use of treatment techniques.

\section{INTRODUÇÃO}

O planeta terra tem uma grande amplitude de ocupação de água, dados quantitativos afirmam que dois terços da superfície do planeta são ocupados por água, destes $2 \%$ são de água doce apta para o consumo humano (MARENGO, 2008). Assim, levanta-se a preocupação e requer além de atenção, intervenção, visto que trata-se de uma população que vive em um consumismo descontrolado, sem a devida conscientização do uso racional desse recurso.

De acordo com Athayde Júnior et al. (2009) a maior causa das contaminações em lençóis subterrâneos é o crescimento desordenado nas áreas urbanas.

O município de Campina Grande, no estado da Paraíba por sua vez, é considerada uma grande cidade, que está em constante desenvolvimento e isso pode corroborar com maior chance de contaminação dos lençóis freáticos.

Este município possui barragens e açudes que no período da pesquisa estavam secos em decorrência do longo período de estiagem que assolou a região, e os que continuavam com capacidade hídrica estavam impróprios para o consumo por ter deságue de esgoto, uma vez que o crescimento desordenado das cidades tem transformado os recursos hídricos em receptáculo natural de diversos tipos de poluentes de origem orgânica e inorgânica das mais variáveis fontes.

Os reservatórios do Nordeste apresentam níveis volumétricos mínimos, justificado por altas temperaturas, estas por sua vez, levam a evaporação da água de lagos e açudes, que atrelados aos baixos índices pluviométricos registrados nos últimos anos e as iniciativas governamentais insuficientes, constituem-se assim situação de calamidade (RAMOS; REBELLO, 2016).

O Brasil é possuidor do maior volume de água doce da Terra, porém, nos últimos anos tem passados por sérios problemas de desabastecimento para o consumo humano, além disso, fontes naturais de fornecimento de água agonizam 
SOUSA, M. M. et al. Análise microbiológica de água de poços para abastecimento urbano, na cidade de Campina Grande-Paraíba. In: II Congresso Paraibano de Agroecologia \& IV Exposição Tecnológica, 2019. Anais... Caderno Verde de Agroecologia e Desenvolvimento Sustentável, Pombal, v. 9, n.7, e-7044, 2019.

com a poluição, seja ela gerada no ambiente urbano, rural, e por dejetos de origem industrial (VIEIRA, ALVES e ALVES, 2012).

No Brasil, a portaria $\mathrm{n}^{\circ} 2914 / 11$, do Ministério da Saúde, estabelece os procedimentos e responsabilidades relativos ao controle e vigilância da qualidade da água para o consumo humano e seus padrões de potabilidade, definindo os padrões microbiológicos, físicos químicos e radioativos, de modo que não ofereçam riscos à saúde (BRASIL, 2011).

E dos parâmetros microbiológicos estão bactérias que pertencem ao grupo dos coliformes totais, são classificadas como Bacilos Gram Negativos, aeróbicos ou anaeróbios facultativos, não formadores de esporos, capazes de crescer na presença de sais biliares ou outros compostos ativos de superfície, com propriedades similares de inibição de crescimento e que fermentam a lactose com produção de ácidos aldeídos e gás a $35^{\circ} \mathrm{C}$ em 24 a 48 horas. Já os coliformes fecais ou coliformes tolerantes são bactérias capazes de desenvolver e/ou fermentar a lactose com produção de gás a $44^{\circ} \mathrm{C}$ em 24 horas (BETTEGA et al., 2006).

Vários fatores podem ser responsáveis pela contaminação de corpos hídricos, dentre eles, as práticas de lançamento de dejetos, a localização dos poços subterrâneos, assim como o tempo de construção e a profundidade dos mesmos (FERNANDES, 2012). Em detrimento do exposto objetivou-se com esta pesquisa avaliar os indicadores microbiológicos com possíveis riscos à saúde coletiva da água de poços usados para consumo.

\section{MATERIAL E MÉTODOS}

A pesquisa foi iniciada com divisão das áreas de coleta foi dada em quatro regiões da cidade (norte, leste, sul e oeste); nessas foram selecionados poços específicos para coleta das amostras (quadro 1). A distribuição dos pontos de amostragem se deu pelos bairros da cidade, através desta divisão foram realizadas cinco coletas durante os meses de Junho a Agosto do ano de 2016.

Quadro 1: Coordenadas dos pontos de amostragem nos bairros da cidade de Campina Grande.

\begin{tabular}{|l|l|l|l|l|}
\hline Região & Local (Barrios) & Latitude & Longitude & Altitude \\
\hline Norte & Centro & -7.2172785 & -35.8848555 & 559 metros \\
\hline Leste & José P. & -7.2242869 & -35.87543 & 519 metros \\
\hline Sul & Itararé & -7.26192521 & -35.86257219 & 426 metros \\
\hline Oeste & Santa Rosa & -7.2423071 & -35.9030846 & 525 metros \\
\hline
\end{tabular}

As amostras de água coletadas para análise microbiológica foram armazenadas em recipientes de vidro de 250 $\mathrm{ml}$, devidamente identificados e esterilizados em autoclave. Após a coleta, estas foram acondicionadas em recipiente térmico para posterior análise em laboratório. A água dos poços estavam encanadas e abasteciam residências, na casa antes de fazer a coleta da água, as torneira foram flambadas com isqueiro e abertas para que a partir disso permitisse que a água fluísse livremente por aproximadamente 2 minutos antes de ser armazenada, foi a coletado de $100 \mathrm{ml}$ da água no recipiente, que previamente foi autoclavado, no Laboratório de Microbiologia e Imunologia da UNIFACISA, após a coleta foi realizada assepsia dos frascos estéreis em álcool $70 \%$, depois armazenados em uma pequena caixa de isopor com gelo para manter a integridade das amostras, e levados ao Laboratório de Microbiologia e Imunologia do UNIFACISA - Centro Universitário, onde posteriormente foram feitas as análises da água.

Para as análises das amostras foram utilizados o método da fermentação em tubos múltiplos, em série de três, com a contagem posterior através da técnica do Número Mais Provável (NMP), de acordo com a metodologia descrita na Instrução Normativa 62/2003, do Ministério da Agricultura, Pecuária e Abastecimento (BRASIL, 2003). Aplicou-se ao método em fase de análises que foram divididos em três fases: F1. Fase Primária; F2. Fase Secundária e F3. Fase Terciária.

F1: Cada amostra foi diluída inicialmente em diluente- água peptonada seguindo uma proporção de 1:9 (1 ml de amostra para $9 \mathrm{ml}$ de Diluente), foram feitas 3 diluições 1,0, 0,1 e 0,01 ml.

F2: Das diluições de cada amostra foram transferidos $10 \mu \mathrm{L}$ para tubos de ensaios correspondentes ao caldo Lactose Verde Brilhante uma solução que atua como indicador e que que adicionado o tubo de Durhan invertido para confirmação do desenvolvimento dos microrganismos, em seguida são transportados para estufa bacteriológica a $35 \pm$ $2^{\circ} \mathrm{C}$ por 24 horas. A Confirmação do desenvolvimento dos coliformes deu-se pela presença formação de gás decorrente da fermentação no tubo de Durhan.

F3: Dos tubos que tiveram confirmação de desenvolvimento de coliformes totais foram transferidos $10 \mu \mathrm{L}$ para um novo tubo de ensaio com o Caldo EC que também possuiu o tubo de Durhan invertido, em seguida foi transportado para a estufa bacteriológica a $44^{\circ} \mathrm{C}$ por 24 horas. A confirmação foi feita da mesma forma que os coliformes totais.

Segundo a portaria MS 518/2004 artigo 11, em amostras individuais procedentes de poços, fontes, nascentes e outras formas de abastecimento sem distribuição canalizada, tolerou-se a presença de coliformes totais, na ausência de Escherichia coli/ou coliformes termotolerantes, nesta situação foi investigada a origem da ocorrência, e tomadas as providências imediatas de caráter corretivo e preventivo e realizando nova análise de coliformes totais. 
SOUSA, M. M. et al. Análise microbiológica de água de poços para abastecimento urbano, na cidade de Campina Grande-Paraíba. In: II Congresso Paraibano de Agroecologia \& IV Exposição Tecnológica, 2019. Anais... Caderno Verde de Agroecologia e Desenvolvimento Sustentável, Pombal, v. 9, n.7, e-7044, 2019.

\section{RESULTADOS E DISCUSSÕES}

Quando analisada a ausência ou presença de Coliformes Totais e Coliformes Fecais apresentados nos poços das regiões estudadas no município de Campina Grande, verificou-se que a região Sul apresentou o maior número de contaminação por coliformes termotolerantes e todas as amostras verificou-se contaminação por E. Coli ( Tabela 1). A região norte apresentou contaminação baixa de coliformes termotolerantes e ausência de contaminação por E. Coli, um quatro das cinco amostras analisadas. Na região Leste e região Oeste apresentaram contaminação por coliforme termotolerante e ausência de contaminação por E. Coli. em todas as amostras.

Tabela 1: Resultados das análises microbiológicas realizadas nas águas de poços cartesianos.

\begin{tabular}{|c|c|c|c|c|}
\hline Regiões & Amostras & $\begin{array}{c}\text { Coliformes } \\
\text { termotolerantes } \\
(\mathrm{NMP} / \mathrm{mL})\end{array}$ & $\begin{array}{c}\text { E. Coli } \\
(\mathrm{NMP} / \mathrm{mL})\end{array}$ & $\begin{array}{c}\text { Padrão } \\
\text { estabelecido pela } \\
\text { legislaçâa }{ }^{*}\end{array}$ \\
\hline Sul & $\begin{array}{l}1 \\
2 \\
3 \\
4 \\
5\end{array}$ & $\begin{array}{l}3,6 \times 10^{1} \\
3,6 \times 10^{1} \\
1,5 \times 10^{1} \\
1,5 \times 10^{1} \\
3,6 \times 10^{1}\end{array}$ & $\begin{array}{c}7,4 \\
7,4 \\
1,5 \times 10^{1} \\
1,5 \times 10^{1} \\
7,4\end{array}$ & $\begin{array}{l}\text { AUSENTE } \\
\text { AUSENTE } \\
\text { AUSENTE } \\
\text { AUSENTE } \\
\text { AuSENTE }\end{array}$ \\
\hline Norte & $\begin{array}{l}1 \\
2 \\
3 \\
4 \\
5\end{array}$ & $\begin{array}{c}2,1 \times 10^{1} \\
2,1 \times 10^{1} \\
>1,1 \times 10^{3} \\
2,1 x^{1} \\
2,1 x^{1}\end{array}$ & $\begin{array}{l}\text { AUSENTE } \\
\text { AUSENTE } \\
>1,1 \times 10^{3} \\
\text { AUSENTE } \\
\text { AUSENTE }\end{array}$ & $\begin{array}{l}\text { AUSENTE } \\
\text { AUSENTE } \\
\text { AUSENTE } \\
\text { AUSENTE } \\
\text { AusENTE }\end{array}$ \\
\hline Leste & $\begin{array}{l}1 \\
2 \\
3 \\
4 \\
5\end{array}$ & $\begin{array}{c}6,2 \\
<3,0 \\
<3,0 \\
<3,0 \\
6,2\end{array}$ & $\begin{array}{l}\text { AUSENTE } \\
\text { AUSENTE } \\
\text { AUSENTE } \\
\text { AusENTE } \\
\text { AUSENTE }\end{array}$ & $\begin{array}{l}\text { AUSENTE } \\
\text { AusENTE } \\
\text { AusENTE } \\
\text { AusENTE } \\
\text { AusENTE }\end{array}$ \\
\hline Oeste & $\begin{array}{l}1 \\
2 \\
3 \\
4 \\
5\end{array}$ & $\begin{array}{c}1,1 \times 10^{1} \\
1,1 \times 10^{1} \\
<3,0 \\
<3,0 \\
1,1 \times 10^{1}\end{array}$ & $\begin{array}{l}\text { AUSENTE } \\
\text { AUSENTE } \\
\text { AUSENTE } \\
\text { AUSENTE } \\
\text { AuSENTE }\end{array}$ & $\begin{array}{l}\text { AUSENTE } \\
\text { AUSENTE } \\
\text { AUSENTE } \\
\text { AusENTE } \\
\text { AusENTE }\end{array}$ \\
\hline
\end{tabular}

* Portaria MS 518/2004.

Em análises da fase secundária (F2) realizadas para coliformes termotolerantes apresentaram crescimento em todas as amostras, mostrando assim possibilidades de contaminação em uma das amostras isolada de uma região (Tabela 1). A fase três só foi executada por conta da confirmação do crescimento microbiano, ao que se refere à presença de coliformes, nessa, por sua vez, todas as amostras foram inoculadas no caldo EC (meio de cultivo para demonstração seletiva de coliformes termotolerantes, que tem como principal representante a Escherichia coli), e apresentou uma confirmação parcialmente da ausência e a presença da espécie Escherichia coli. Nas amostras das regiões Leste, Oeste e Norte as amostras 1,2,4 e 5 apresentaram ausência. Já na região Norte, na amostra 3 e na região Sul em todas amostras foram apresentados crescimento para Escherichia coli.

De acordo com a resolução CONAMA (Conselho Nacional de Meio Ambiente) $n^{\circ} 396$, de 3 de abril de 2008, a água deve apresentar ausência de coliformes totais e E.coli, visto sua utilização para consumo humano. Assim, as amostras analisadas se apresentam em não conformidade. As resoluções consultadas sugerem que quando encontrados resultados positivos para estes micro-organismos devem ser adotadas ações corretivas (BRASIL, 2011), recomenda-se o processo de cloração, por meio do sistema de aplicação de cloro por gotejamento.

Notou-se a presença de coliformes totais em $100 \%$ das amostras analisadas, ou seja, as quatro regiões apresentaram contaminação; referente ao E.coli, detectou-se a presença em $30 \%$ das amostras, correspondendo à todas da região sul (5) e apenas uma da região norte. Os dois microrganismos causam comprometimento na qualidade da água , uma vez que a mesma deve atender os parâmetros estabelecidos por legislações vigentes federais e estaduais. Através de revisões na literatura foram encontrados estudos semelhantes na área, que detectaram a presença dos mesmos microrganismos. No trabalho de GOMES, D. J. et al. (2016), intitulado: “Qualidade microbiológica de água de poços artesianos no município de Sousa-PB”, alcançou resultados positivos para presença de Coliformes Totais e de E.Coli. Em que $100 \%$ das suas amostras houve contaminação com coliformes totais totais e $75 \%$ das amostras para E.coli. 
SOUSA, M. M. et al. Análise microbiológica de água de poços para abastecimento urbano, na cidade de Campina Grande-Paraíba. In: II Congresso Paraibano de Agroecologia \& IV Exposição Tecnológica, 2019. Anais... Caderno Verde de Agroecologia e Desenvolvimento Sustentável, Pombal, v. 9, n.7, e-7044, 2019.

Além disso, os autores afirmam que a proximidade com fossas sépticas foi umas das prováveis causas para a contaminação da água.

A presença de coliformes totais e de E.coli encontrados nas amostras de águas analisadas comprovam as suspeitas de contaminação, pois os dois microrganismos estão vinculados à presença de fezes. Essa evidência, provavelmente está associada à proximidade dos poços à percursos de redes de esgotos, de fossas desativadas e redes públicas de coleta de resíduos líquidos, comprometendo a água do lençol freático da área analisada, o que torna a água dos poços inaptas ao consumo humano, podendo trazer riscos especialmente à saúde pública,pois boa parte da população não tem consciência de que essa água precisa passar por um tratamento de purificação, tais como: fervura, cloração ou a desinfecção do poço e da caixa d’água; sendo o último um processo demorado mas que garante a qualidade da água ser consumida.

\section{CONCLUSÃO}

De acordo com esse estudo pode-se observar que a água coletada nos quatro poços monitorados nas regiões Norte, Sul, Leste e Oeste do município, apresentaram contaminação o que torna a água imprópria para o consumo humano segundo a Portaria 2.914 de 12 de dezembro de 2011, do Ministério da Saúde, a qual estabelece a ausência de coliformes totais e coliformes termotolerantes em amostras de $100 \mathrm{~mL}$.

\section{REFERÊNCIAS}

ATHAYDE JÚNIOR, G. B.; NÓBREGA, C. C.; GADELHA, C. L. M.; SOUZA, I. M.F.; FAGUNDES, G. S. Efeito do antigo Lixão do Roger, João Pessoa, Brasil, na qualidade da água subterrânea local. Ambi-Agua, Taubaté, v. 4, n. 1, p. 142-155, 2009.

BETTEGA, Janine Maria Pereira Ramos et al . Métodos analíticos no controle microbiológico da água para consumo humano. Ciênc. agrotec., Lavras , v. 30, n. 5, p. 950-954, Oct. 2006 . Available from <http://www.scielo.br/scielo.php?script=sci_arttext\&pid=S1413-70542006000500019\&lng=en\&nrm=iso>. access on 21 Sept. 2019. http://dx.doi.org/10.1590/S1413-70542006000500019.

Brasil. Ministério da Saúde. Portaria n. 518, de 25 de março de 2004. Estabelece os procedimentos e responsabilidades relativas ao controle e vigilância da qualidade da água para consumo humano e seu padrão de potabilidade, e dá outras providências.

BRASIL. Portaria 2.914, de 12 de dezembro de 2011. Dispõe sobre os procedimentos de controle e de vigilância da qualidade da água para consumo humano e seu padrão de potabilidade. Brasília, DF: Governo Federal, 2011.

BRASIL. Conselho Nacional do Meio Ambiente. Resolução Conama no 357, de 17 de mar. de 2005. In: Conselho Nacional do Meio Ambiente. 2. ed. Brasília: CONAMA, 2008.

BRASIL. Ministério da Saúde. Inspeção sanitária em abastecimento de água. Série A: normas e manuais técnicos. Brasília, 2006.

BURTON, G. R. W.; ENGELKIRK, P. G. Microbiologia para ciências da saúde.7.ed. Rio de Janeiro: Guanabara Koogan, 2005.

DE OLIVEIRA, Adriana Carla et al. Análise microbiológica da água de minas e poços semiartesianos de santa fé do sul, sp. REVISTA FUNEC CIENTÍFICA-MULTIDISCIPLINAR, v. 2, n. 4, 2013.

Diário Oficial da União, Brasília, v.141, n.59, p.266, 25 mar. 2004. Seção 1. BRASIL, Portaria $n^{\circ} 2914$ de 12 de dezembro de 2011. Brasília: Ministério da Saúde, 2011.

FERNANDES, A.M.F. Diagnóstico da qualidade da água subterrânea em propriedade rural no município de Planalto, RS. 2012. Disponível em:bibliodigital.unijui.edu.br.

FERREIRA, Antonio Flávio Arruda; CAPPI, Nanci; DOS SANTOS, Tânia Mara Baptista. Análise de bactérias indicadoras de poluição fecal em águas de poços localizados na cidade de Anastácio-MS. ANAIS DO ENIC, v. 1, n. 2, 2015 .

GMBH, Vivid Planet Software. Mapcoordinates: Find Google Maps coordinates easily. 2015. Disponível em: \&lt;http://www.mapcoordinates.net/pt\&gt;. Acesso em: 23 fev.2017. 
SOUSA, M. M. et al. Análise microbiológica de água de poços para abastecimento urbano, na cidade de Campina Grande-Paraíba. In: II Congresso Paraibano de Agroecologia \& IV Exposição Tecnológica, 2019. Anais... Caderno Verde de Agroecologia e Desenvolvimento Sustentável, Pombal, v. 9, n.7, e-7044, 2019.

GUILHERME, E.F.M., SILVA, J.A.M. Pseudomonasaeruginosa, como indicador de como indicador de contaminação hídrica. Revista Higiene Alimentar, v.14, n.76, p.43 47, 2000.

GOMES, Damião Junior et al. Qualidade microbiológica de água de poços artesianos no município de Sousa-PB. Informativo Técnico do Semiárido, v. 10, n. 1, p. 99-105, 2016.

IBGE - INSTITUTO BRASILEIRO DE GEOGRAFIA E ESTATÍSTICA. IBGECidades - censo 2014. Disponível em: http://www.ibge.gov.br/. Acesso em: 03 dez. 2015.

INSTITUTO GEOLÓGICO E MINEIRO, “Água Subterrânea: Conhecer para Preservar o Futuro”, 2001, disponível no site do INETI: http://eGeo.ineti.pt/geociencias/edicoes_online/diversos/agua_subterranea/ indice.htm.

MARENGO, J. A. Água e mudanças climáticas.v.22, n. 63, p. 83-96, 2008. OKURA, M. H.; SIQUEIRA, K. B. Enumeração de coliformes totais e coliformes termotolerantes em água de abastecimento e de minas. Revista Higiene Alimentar, São Paulo, v. 19, n. 135, p. 86-91, set. 2005.

RAMOS, Andrea Malheiros; REBELLO, Expedito Ronald G. Situação da seca observada nas regiões Norte e Nordeste do Brasil em 2016. Brasília: Inmet, 2016. $8 \mathrm{f}$.

SANTOS, A. C. M. et al. A virulência de Escherichia coli patogênica extra intestinal (ExPEC) em relação à idade e ao sexo do hospedeiro. São Paulo, 2009. Disponível em: Acesso em: 05 out. 2013.

SILVA, C.A; OLIVEIRA RIBEIRO, C.A.; KATSUMITI, A..; ARAUJO, M.L.; ZANDONA,E.M.; SILVA DE ASSIS, H.C. Evaluation of waterborne exposure to oil spill 5 years after an accident in Southern Brazil.Ecotoxicol. Envirion. Saf. v.72, n. 2, p.400 409, 2009.

VIEIRA, D. L. M.; ALVES, G. M.; ALVES, C. E. S. Estudo da viabilidade do uso da água da chuva em lava rápido. VI Mostra Interna de Trabalhos de Iniciação Científica do curso de Engenharia Ambiental e Sanitária do Centro Universitário Maringá - Cesumar, Maringá-PR, 2012.

\section{AGRADECIMENTOS}

Apoio financeiro: Fundação de Apoio à Pesquisa do Estado da Paraíba - FAPESQ. 